\title{
Impact of Lean Utilization on Operational Performance: A Study of Sri Lankan Textile and Apparel Industry
}

\author{
G.C.I. Gunarathne \\ University of Peradeniya, Sri Lanka \\ W.D.C.K.T. Kumarasiri \\ University of Peradeniya, Sri Lanka
}

\begin{abstract}
The increasingly competitive local and international market for the Textile and Apparel industry has forced the manufacturers to adopt practices that lead to cost reductions and improve Operational Performance (OP). According to Gamage et al. (2010) lean had been initiated to fulfill this requirement. Yet it was crucial to be aware whether Lean Practices would essentially have a positive impact on $O P$. This research was therefore conducted to identify the relationship between Lean and OP and the impact Lean utilization creates on the $O P$ levels. The objectives also covered the identification of issues that hinder the ability to derive the expected benefits and suggesting how Lean could be used effectively to attain the expected OP levels. A survey questionnaire was used to gather data from Textile and Apparel factories that met the criteriaof possessing Lean manufacturing as the standard of operation for more than a period of one year, to ensure adequate time to gain results on an impact on the OP measurement criteria identified in the model. This was studied in a sample of thirty medium to large scale factories registered in the Board of Investments. Data were specifically gathered on Lean utilization under three constructs, Just in Time (JIT), Waste Elimination (WE) and Flow Management (FM) extracted
\end{abstract}

\section{Corresponding Author:}

Mr. G.C.I.Gunarathne is a Lecturer at the Department of Operations Management, University of Peradeniya, Peradeniya, Sri Lanka. E-mail: isurugune.jp@gmail.com 
from literature. OP was measured through 12 Key Performance Indicators identified from industry. Descriptive Statistics, Multiple Regression Analysis and Correlation Analysis were employed to analyze the data. Results indicated that there is a positive relationship between Lean Utilization and $O P$ in the Textile and Apparel industry. WE techniques utilized in the industry had a highly significant relationship with OP compared to JIT and FM. Also it was evident that lack of awareness of the human factor, lesser number of studies and consultancy expenses has hindered their ability to gain expected outcomes. The study encourages WE techniques such as elimination of bottlenecks and would support the management in long term decision making.

\section{Keywords}

Key Performance Indicators, Lean Practices, Operational Performance, Textile and Apparel Industry

\section{Introduction}

The apparel industry has become a major player in the Sri Lankan economy which is measured by the gross domestic product. As per the Export Development Board (2015), the apparel industry has contributed to 43 per cent of the total exports of the country. 70 per cent of the country's industry exports are through apparel manufacturing (Abeysinghe, 2014).

Apparel is an assembly oriented labor intensive industry which has lot of human involvement which is at the same time prone to error and waste. Lean is a systematic approach to identify and eliminate waste of the products in accordance to customer requirement. A performance measurement method to assess the leanness of operations, to identify whether lean tools and principles have been effectively utilized, is important for future decision making towards progression of the apparel sector of the country. This will assist in revealing whether application of lean has been a reason for any performance improvement of the manufacturing process. But firms often fail to maximize the benefits of lean strategies because they often fail to develop the performance measurement metrics needed to evaluate the improvement in effectiveness and efficiency (Gunasekaran et al., 2004). As per the views of the lean officials in the Sri Lankan context, minimal efforts have been made to establish proper Lean metrics in most of 
the apparel factories running with a Lean touch. The research problem is therefore identified as "What is the impact of Lean Utilization on OP in the textile and apparel industry of Sri Lanka?", to cater a contemporary need, with the intention of measuring whether Lean tools utilization has been a reason to improve the performance levels and also to pinpoint what weaknesses in utilization of Lean tools resulted in unimpressive results for apparel manufacturers of the nation. The main objectives of the research were to study the extent to which Lean Utilization influences on the Operational Performance of textile and apparel manufactures in Sri Lanka and to explore the levels of impact of three types of Lean tool utilization on the Operational Performance of textile and apparel manufacturers in Sri Lanka. It is also intended to make suggestions where applicable to solve the issues in practicing Lean in the industry.

The findings of the study are generally important for the middle and lower level management of apparel factories in assessing the leanness of their entities through the framework created based on literature and industry information. It will enable them to make inter-firm and intra-firm comparisons of performance and take measures of improvement where necessary. The top management would be benefitted with the ability to correct decisions for the future, with the awareness of current success rate with regard to Lean initiatives. The ground level/operational level workers (team players) would derive benefits if the research could identify how Lean tools could optimize the labor hours. This will inevitably reduce the stress of defects and rework for the team players. Also the overall reduction in costs and improved profits of the firm will indirectly benefit the workers through financial means such as salary increments and also through non-financial means such as recognition and self-esteem.

The rest of the paper consists of four sections. The first section presents the literature review, the second section presents the research methodology and the third is the analysis of the collected data. Finally, section four concludes and discusses the limitations and implications of the research. 


\section{Literature Review}

Lean is derived from the Japanese concept TPS, Toyota Production System. It is the Pull based manufacturing which was established in 1970's by TaichiOhno and Shigeo Shingo at Toyota Motor Company (Hokoma et al., 2010). The term "lean" means a series of activities or solutions to minimize waste and Non-Value Added operations (NVA), and improve the Value Added (VA) process (Karim et al., 2013). Waste could be identified as any activity that is not being paid by the customer. TPS has identified seven major types of non-value-adding activities as waste in business or manufacturing processes (Liker, 2004). Even though being identified as elimination of waste, Lean has a total philosophy behind it. Liker (2004) has also identified Lean as, "developing principles that are right for your organization and diligently practicing them to achieve high performance that continues to add value to customers and society". It is a way of thinking rather than another operations improvement technique. For this study, "Lean" has been identified under 13 practices derived from Rahman, Laosirihongthong and Sohal (2010) which will be further described throughout. The export-apparel manufacturing industry together with textile is the leading manufacturing industry in Sri Lanka that has emerged as the country's main export earner and the largest single employment provider in the industrial sector (Department of Census and Statistics of Sri Lanka, 2009).As being identified by Dheerasinghe (2009), cited in Gamage et al., (2010) "this industry provides more than 330,000 direct employment or 5 percent of country's total employment in more than 1,060 garment factories", which suggests the importance of the industry to the country specifically on two aspects, employment generation and export income. Operational Performance could be identified as the performance of an entity against predetermined standards, such as compliance for regulations, waste reduction or elimination, productivity, etc.(Garner \& Black, 1999).

\section{Lean in Textile and Apparel Industry of Sri Lanka}

Since the mid-2000s, export-apparel manufacturers in Sri Lanka identified possibilities for them to turn to lean production for improving the efficiency of production systems (Wickramasingha \& Wickramasingha, 2010). Lean was first implemented as an improvement method at MAS Intimates Linea Clothing Pallekale in 2005. Only handful number of companies has implemented Lean in Sri Lanka. It can be seen that apart from the other 
organizations, many apparel organizations have taken lots of initiatives to implement Lean Manufacturing in their organizations (Silva et. al., 2011, p.2). As per their identifications, $5 \mathrm{~S}$ that stands for Sort (Seiri), Simplify (Seiton), Shine (Seiso), Standardize (Seiketsu) and Sustain (Shitsuke),Value Stream Map (VSM), Takt time, One Piece Flow, Cellular manufacturing, Single Minute Exchange of dies (Changeover time), Kaizen and pull system are the most common tools utilized in the Sri Lankan context in their order of implementation.In the Sri Lankan context, it was understood that lean manufacturing is not a widely practiced tool yet in the Sri Lankan apparel industry though the topic is being widely discussed. Authors believe that it is due to the difficulty of adapting into the lean culture where a wellorganized approach is essential (Gamage et al., 2010).

\section{Lean and Operational Performance Measurement}

Incorrect application of lean strategies results in inefficiencies of an organization's resources and reduced employee confidence in lean strategies (Marvel et al., 2009). According to Womack and Jones (2003), the implementation order would be the same for any industry. But the need for an intense culture study for any entity prior to implementation needs to be highlighted.

A proper assessment methodology to determine whether the expected benefits are derived from Lean implementation should essentially be there in order to justify the investments made. Measuring leanness and the selection of right measuring metrics with appropriate implementation method is very crucial (Karim et al., 2013). It will act as a base for the identification of how Lean has led to improved performance in the factory context. Different researchers have considered different indicators to define and identify performance improvement. Kumar and Sampath. (2012) have identified level of Work in Progress(WIP) as an indicator of performance and have investigated on how lean applications such as cellular layout could affect WIP levels. They have proved that shifting to a cellular layout could reduce the WIP 70 per cent - 80 per cent and the resulting reduction in nonvalue adding activities could reduce the lead time from 2 days to 20 minutes. Karim et al. (2013) developed a leanness evaluation metric on the basis of Continuous Performance Measurement (CPM). There they used the effectiveness and efficiency of the production as indicators of performance 
of an entity. It is therefore evident that previous research provides support for a significant direct relationship between utilization of lean tools and increased performance for manufacturing organizations.

Rahman, Laosirihongthong and Sohal (2010), in their research model have identified 13 lean practices to measure the leanness of a manufacturing facility. Principal component analysis identified these practices under three constructs as JIT (first six scales), Waste Minimization/Elimination (second four scales) and Flow Management (final three scales).

Using data collected from 187 manufacturing companies in Thailand, this research examined the extent to which lean practices are adopted by manufacturing organizations and their impact on firms' operational performance. Operational performance was measured using 4 matrixes and the results have proved that there is a positive relationship between lean practices and operational performance.

The above model will be utilized in this research. JIT has been a key element in developing lean manufacturing in a lot of firms (Hines, 1996). Rahman, Laosirihongthong and Sohal (2010) have further identified this as postponing of unnecessary resources until they are required. The second construct identified in this model is Waste Elimination. As per Tapping (2006), the primary purpose of a lean strategy is muda (waste) elimination. Waste is everything that does not add value to a production process (Womack \& Jones, 1996). Flow Management, which is the final construct, could be identified as "reducing management or coordination costs"(Rahman, Laosirihongthong \& Sohal, 2010). Operational performance based on this model will be measured through a criteria of quick delivery, cost per unit and customer satisfaction. Even though Rahman, Laosirihongthong and Sohal (2010) have measured performance with comparison to the industry leader, this research will identify the KPIs of the criteria and measure longitudinally. 


\section{Issues regarding Lean in the Textile and Apparel Industry}

As per the findings of Hodge et al. (2011) based on 11 garment factories in North and South Carolina, USA, factors such as reluctance of shop floor employees to give suggestions, training issues especially in relation to the language use and mindset of employees that machinery should always be running due to the heavy workload are the main contributors that affects smooth lean operations. They have also identified resistance to change of both shop floor employees and management as a major crisis with regard to Lean. Kovacheva (2010) has further analyzed this issue with the tendency of the factory floor employees to leave the company right with the initiation of Lean. According to Silva et.al. many apparel organizations have taken lots of initiatives to implement Lean manufacturing in their organizations. But the most common mistake they have made is that they try to adapt the tools of Toyota Production System without adapting the underlined philosophy Lean Manufacturing.

\section{Research Methodology}

\section{Research Design}

This research was designed as a field study with reference to the Textile and Apparel Industry of Sri Lanka. This could be identified as the most significant industry which has vastly embraced Lean and derived significant benefits in the Sri Lankan context. When analyzing the market it is also evident that most of the emerging apparel and textile manufacturers, specifically who are in to bulk production are keen to adopt Lean given the visible benefits of the practices. This research had primarily taken a quantitative approach where data was collected and analyzed through statistical means. The type of the investigation was correlational, trying to identify a relationship between implemented lean tools and operational performance in a non-contrived factory setting.

The three Lean Constructs, JIT, WE and FM were identified directly from the model used by Rahman, Laosirihongthong and Sohal (2010), which was derived from principle component analysis. The first 6 practices, Reducing Setup Time, Preventive Maintenance, Cycle Time Reduction, Reducing Inventory, New process Equipment and Technology and Quick Change over Techniques were identified here as JIT Practices. The next 4 Practices, Kanban, Removing Bottlenecks, Poka Yoke and Waste 
Elimination Measures were identified as WE Practices in this model. Finally the last 3 Practices, Reducing Production Lot Sizes, Focusing on a Single Supplier and One Piece Flow were identified under Flow Management Practices. Only these 3 Lean Constructs were adopted for this study based on Rahman, Laosirihongthong and Sohal's (2010) model as their findings have been realized as reliable and generalizable.

Figure 1: Conceptual Model

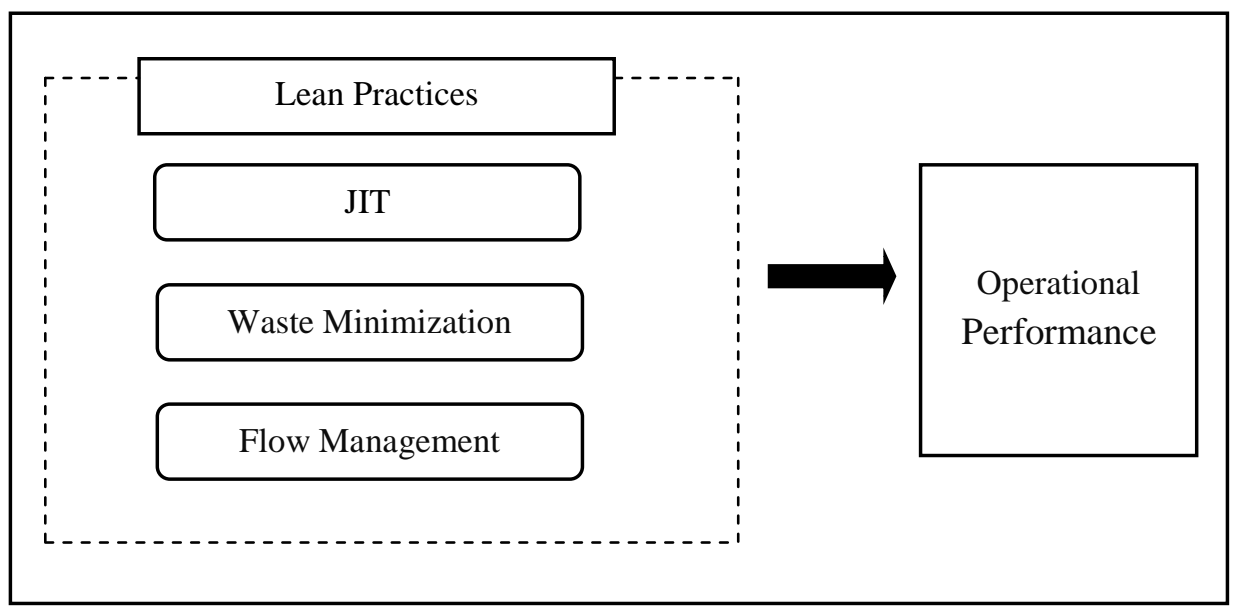

Source: Authors

Operational Performance Measures were also identified from Rahman, Laosirihongthong and Sohal (2010)'s model where 3 indicators were selected as Quick Delivery, Cost per Unit and Customer Satisfaction for this study purpose. The indicators of these measures were derived directly from the industry. According to Gamage et al. (2010) "In identifying the impact of lean practices in any organization, it is essential to have industry specific indicators. But the published literature lacks such lean indicators specific to the apparel sector". Therefore this study also focused on KPIs derived from the industry to measure the Operational Performance under the 3 Measures in order to create a realistic impression to the users of the findings. The alternative hypothesizes were derived as follows.

H1: Utilization of Lean practices has an impact on the Operational Performance of textile and apparel manufacturing firms 
H2: Just-In-Time (JIT) has an impact on the Operational Performance of textile and apparel manufacturing firms

H3: Waste elimination (WE) has an impact on the Operational Performance of textile and apparel manufacturing firms

H4: Flow Management (FM) has an impact on the Operational Performance of textile and apparel manufacturing firms

\section{Target Population and Sampling Technique}

The population was identified as the medium to large scale apparel manufacturers who have adopted Lean as their standard of operation at least to the main value adding process. Textile and Apparel factories that met the above criteria of possessing Lean manufacturing as the standard of operation for more than a period of one year, to ensure adequate time to gain the expected impacts on Operational Performance measures identified in the model. This accounted for thirty medium to large scale factories registered by the BOI. The entire population was studied to ensure an effective survey to find solutions for the derived questions.

No specific sampling technique was utilized in this study as the sample was same as the market population. This was due to the limited number of factories that satisfied the above mentioned characteristics. This sample size which is equal to the population eliminated sample bias and enabled the researcher to make confident conclusions on the impact of Lean on operational performance.

Based on previous literature, the most suitable persons to gain information on Lean performance are the Lean Executives and the Senior Management. Therefore the unit of analysis was one lean official from each factory of the sample who has been in office for more than a period of six months to ensure the eligibility in competence and experience to provide reliable answers to the questions.

\section{Data Analysis}

\section{Reliability and Validity}

As shown in Table 1, internal reliability is measured using Cronbach alpha value and values were reported above 0.7 level. All variables had a positive 
scale score of Item Total correlation which is greater than 0.25 level. Multivariate assumption was assessed and confirmed a satisfactory level.

Table 1: Reliability and Validity Summary

\begin{tabular}{cccccc}
\hline Variable & $\begin{array}{c}\text { No. of } \\
\text { Items }\end{array}$ & Mean & $\begin{array}{c}\text { Standards } \\
\text { Deviation }\end{array}$ & $\begin{array}{c}\text { Cronbach } \\
\text { Alpha } \\
\text { Reliability }\end{array}$ & $\begin{array}{c}\text { Item Total } \\
\text { Correlation } \\
\text { (Min-Max) }\end{array}$ \\
\hline JIT & 4 & 3.48 & .62 & .795 & $.476-.680$ \\
WE & 4 & 3.42 & .68 & .799 & $.308-.614$ \\
FM & 3 & 3.02 & .72 & .803 & $.295-.548$ \\
OP & 5 & 3.90 & .59 & .838 & $.324-.628$ \\
\hline
\end{tabular}

Note: JIT=Just In Time, WE=Waste Elimination, FM=Flow Management, $O P=$ Operational Performance.

\section{Hypotheses Testing and Findings}

Simple liner regressions were performed to test hypothetical relationship and results were reported in Table 2. It is evident that out of the three Lean constructs waste minimization (WM) uniquely contribute to the model with a Beta value of 0.583 which is statistically significant at $0.03 \quad(\beta=.583$, $\mathrm{p}<0.05)$. Flow Management $(\mathrm{FM})$ contributes to the model with a Beta value of $0.239(\mathrm{p}=0.298)$, but reported as a not significant factor that predicts operational performance. In contrast as per the results in Table 2, JIT does not contribute to the operational performance $(\beta=-0.0323, p>0.05)$. In conclusion, only $\mathrm{H} 3$ is supported where as $\mathrm{H} 2$ and $\mathrm{H} 4$ are not supported. The significant model (WE $\longrightarrow \mathrm{OP}$ ) has a high predictive power which is waste elimination can explain more than 80 percent variation in operational performance.

Table 2: Result of Simple Linear Regression Summary

\begin{tabular}{cccc}
\hline Path & Beta( $(\boldsymbol{\beta})$ & Significance & $\begin{array}{c}\text { Adjusted R- } \\
\text { squared }\end{array}$ \\
\hline $\mathrm{JIT} \longrightarrow$ OP & -0.0323 & .222 & .254 \\
$\mathbf{W E} \longrightarrow$ OP & .583 & .003 & .818 \\
$\mathbf{F M} \longrightarrow$ OP & .239 & .298 & .734 \\
\hline
\end{tabular}

Note: JIT=Just In Time, WM=Waste Elimination, FM=Flow Management, $O P=$ Operational Performance. 


\section{Discussion}

It could be concluded that in the Sri Lankan context more impact is created on operational performance through Waste Elimination practices. It could be therefore be recommended to focus more on Waste Elimination measures such as, using Pull based production system/ Kanban cards, removing Bottlenecks, Error Proof techniques/ Poka Yoke and waste elimination methods. Similar to the findings by Rahman, Laosirihongthong and Sohal (2010), as Flow Management has a much lower level of significance in both Small and Medium Enterprises (SMEs) and Large Enterprises(LEs), this research has identified that flow management practices such as selecting one supplier does the least contribution towards Operational Performance. In contrast the base research has prioritized the JIT techniques as applicable to both SMEs and Les which was also supported by previous research conducted in the West. This research derived contrasting results as comparatively less effective given the popular intensive adaptation. It needs to be notified that there could be other waste elimination practices other than the 4 adapted. According to Paneru (2011), Zero defects and Line Balancing are such major waste elimination techniques where the goal of Zero Defects has been identified as to ensure that products are fault free all the way, through continuous improvement of the manufacturing process (Karlsson \& Ahlstrom, 1996 cited in Paneru (2011). Line Balancing as per the Mid-America Manufacturing Technology Center Press Release (2000), cited by Paneru (2011) is to make every workstation produce the right volume of work that is sent to upstream workstations without any stoppage. This will ensure the synchronization of work at each workstation without being unequally faster or slower than the other. Therefore it should be noted that these techniques could also be researched and tested upon in the Sri Lankan context as Waste Elimination measures which have a higher probability to create a positive impact as the measures being tested in this study. Even though the findings of this research do not contribute towards a one piece flow production line under better Flow Management, Paneru, 2011 has encouraged single piece flow movement of WIP by further moving from long assembly lines to work cells. The findings were that multiskilling and enhanced communication would act positively towards the production efficiency and is even more beneficial in style changes and rework reduction. 
When considering the sample it was realized that the discussion made through academics and industry specialists had not been enough to ensure sustainability of Lean within the country. Also the factors such as employee resistance, top management commitment and lack of awareness how each individual is benefitted through Lean have significantly contributed to hinder factories' ability to derive expected enhancements. With a positive cultural shift and awareness proper means of initiation and localization the expected benefits are comparatively easier to derive.

\section{Theoretical Contribution}

On a theoretical perspective, this research had focused on the Key Performance Indicators (KPIs), identified directly from the industry which adds to the limited number of research in the Sri Lankan context which have considered them. It has presented a better insight for managers to determine whether their expectations are fair by the Lean practices implemented. The research could be expanded in the future in different dimensions of the same conditions such as different level of Lean experience and also to directly get the questionnaires filled by the operational staff etc.

\section{Managerial Contribution}

The findings of this research indicate that Waste Elimination practices facilitate Operational Performance of a firm. The results bring deep insights for managers striving to promote Waste Elimination practices within their organizations. Especially, in order to continuously increase Operational Performance, managers should commit themselves to the practice, and more on internal research and development activities to reduce waste. They could therefore wisely prioritize and reduce the variation of the output. This will enable them to make successful, guided, long term oriented decisions optimizing the resource constraints. Also they would be able to have an idea whether their expectations are fair by the Lean practices implemented.

\section{Limitations}

Research was carried out in a non-contrived factory setting and only 13 Lean practices were identified even though there are numerous other lean practices followed by apparel manufacturers. Even though the research was intending to contact Lean officials from executive or managerial levels, it was evident that some of the factories do not have individuals specifically in 
charge of Lean, which led the data to be gathered from supply chain or ware house executives who were put in charge of Lean Practices in the factory.

\section{References}

Abeysinghe, B. (2014). The time has come for Sri Lanka to look beyond apparel exports. Daily FT. Online available at: http://www.ft.lk /2014/03/21/the-time-has-come-for- exports.

Karim, A., \& Arif-Uz-Zaman, K. (2013). A methodology for effective implementation of lean strategies and its performance evaluation in manufacturing organizations. Business Process Management Journal, 19(1), 169-196.

Belekoukias, I., Garza-Reyes, J. \& Kumar, V. (2014). The impact of lean methods and tools on the operational performance of manufacturing organisations. International Journal of Production Research, 52(18), 5346-5366.

Department of Census and Statistics of Sri Lanka (2009), Census of Industry $-2003 / 2004$.

Online available at: www.statistics.gov.lk/industry/index.htm

Export Development Board (EDB). (2015). Performance of the Export Sector of Sri Lanka Report of Export development Board. Online available at: http://www.srilankabusiness.com

Feld, M.W. (2000). Lean manufacturing: Tools, techniques, and how to use them. The St. Lucie Press: London.

Ferdousi, F. (2009). An investigation of manufacturing performance improvement through lean production: A study on Bangladeshi garment firms. International Journal of Business and Management, 4(9). doi: 10.5539/ijbm.v4n9p106

Gamage, J., Vilasini, P., Perera, H. \& Wijenatha, L. (2010). Impact of lean manufacturing on performance and organisational culture: A case study of an apparel manufacturer in Sri Lanka.

Garner, B., \& Black, H. (1999). Black's law dictionary. Minnesota: West Group.

Gunasekaran, A., Patel, C., \& McGaughey, R.E. (2004). A framework for supply chain performance measurement. International Journal of Production Economics, 87(3), 333-347.

doi: 10.1016/j.ijpe.2003.08.003.

Hines, P. (1996). Purchasing for lean production: The new strategic agenda. International Journal of Purchasing \& Materials Management, 32(1), 2-10.

Hodge, G.L., Ross, K., Joines, J.A., \& Thoney, K. (2011). Adapting lean manufacturing principles to the textile industry. Production Planning \& Control, 22(3), 237-247. doi: 10.1080/09537287.2010.498577. 
Kovacheva, A. V. (2010). Challenges in Lean implementation: Successful transformation towards lean enterprise. Aarhus: University of Aarhus.

Kuhlang, P., Edtmayr, T., \& Sihn, W. (2011). Methodical approach to increase productivity and reduce lead time in assembly and production-logistic processes. CIRP Journal of Manufacturing Science and Technology, 4(1), 24-32.

Kumar, B. S., \& Sampath, V. R. (2012). Garment manufacturing through lean initiative-an empirical study on WIP fluctuation in T-shirt production unit. European Journal of Scientific Research, 73(92), 235-244.

Liker, J.K. (2004). The Toyota way: Fourteen management principles from the world's greatest manufacturer. New York : McGraw-Hill Companies.

Lingereddy, H., Reddy, S.G., Jagadeshwar, K. (2013) 5s as a tool and strategy for improvising the work place. IJAET [online],IV (AprilJune), 28.

Paneru, N., (2011). Implementation of Lean manufacturing tools in garment manufacturing process focusing sewing section of men's shirts. Online available at: https://www.scribd.com/document/213837439/

Hokoma, R. A. (2010). The current awareness of Just-In-Time techniques within the Libyan textile private industry: A case study. International Journal of Mechanical, Aerospace, Industrial, Mechatronic and Manufacturing Engineering, 4(9), 886-889.

Nunesca, R. M., \& Amorado, A. T. (2015). Application of Lean manufacturing tools in a garment industry as a strategy for productivity improvement. Asia Pacific Journal of Multidisciplinary Research, 3(4).

Schonberger, R.J. (2007). Japanese production management: An evolution with mixed success. Journal of Operations Management, 25(2), 403419.

Shah, R., \& Ward, P.T. (2003), "Lean manufacturing: context, practice bundles and performance", Journal of Operations Management, 21, 129-49.

Silva, S.K.P.N., Perera, H.S.C., Samarasinghe., G.D. (2011). Factors affecting successful implementation of lean manufacturing tools and techniques in the apparel industry in Sri Lanka. Online Available at: $\mathrm{http} / / / \mathrm{ssrn} . \mathrm{com} / \mathrm{abstract}=1824419$

Standridge, C.R., \& Marvel, J.H. (2009) Simulation-enhanced lean design process. Journal of Industrial Engineering and Management, 2(1), 90-113.

Tan, K.C. (2001). A framework of supply chain management literature. European Journal of Purchasing \& Supply Management, 7(1), 39-48. 
Tapping, D. (2006). The Lean pocket guide XL - Tools for the elimination of waste. New York: McGraw-Hill.

Wickramasinghe, D., \& Wickramasinghe, V. (2010). Perceived organisational support, job involvement and turnover intention in lean production in Sri Lanka. The International Journal of Advanced Manufacturing Technology, 55(5-8), 817-830.

Wilson, L. (2009). How to implement lean manufacturing? New York: McGraw-Hill.

Womack, J.P., Jones, D.T., \& Ross, D. (1990).The machine that changed the world. New York: Macmillan. 